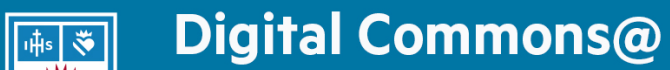

Loyola Marymount University

LMU Loyola Law School

\section{Journal of Catholic Education}

3-19-2013

\section{A Collaborative Approach: Assessing the Impact of Multi-Grade Classrooms}

Rebecca A. Proehl

Shelese Douglas

Dean Elias

Anthony $\mathrm{H}$. Johnson

Wendy Westsmith

Follow this and additional works at: https://digitalcommons.Imu.edu/ce

\section{Recommended Citation}

Proehl, R. A., Douglas, S., Elias, D., Johnson, A. H., \& Westsmith, W. (2013). A Collaborative Approach: Assessing the Impact of Multi-Grade Classrooms. Journal of Catholic Education, 16 (2). http://dx.doi.org/ 10.15365/joce. 1602092013

This Focus Section Article is brought to you for free with open access by the School of Education at Digital Commons at Loyola Marymount University and Loyola Law School. It has been accepted for publication in Journal of Catholic Education by the journal's editorial board and has been published on the web by an authorized administrator of Digital Commons at Loyola Marymount University and Loyola Law School. For more information about Digital Commons, please contact digitalcommons@lmu.edu. To contact the editorial board of Journal of Catholic Education, please email JCE@nd.edu. 


\title{
A Collaborative Approach: Assessing the Impact of Multi- Grade Classrooms
}

\author{
Rebecca A. Proehl, Shelese Douglas, Dean Elias, Anthony H. Johnson, \\ and Wendy Westsmith \\ Saint Mary's College, California
}

Catholic schools in the United States are faced with the looming challenge of declining enrollments. One possible strategy for dealing with this problem is to institute multi-grade classrooms where students from two or more grades are combined in one classroom with one instructor. In this article, the authors examined one urban Catholic school's successful transition to multi-grade classrooms when student enrollment dropped dramatically. The transition to multi-grade classrooms did not have a significant impact on student outcomes as measured by absences, tardiness, or academic performance though other social-emotional and developmental benefits were perceived. For example, the students were more likely to nurture other students and be nurtured by them; assume shared responsibility and leadership in the classroom and at home; were involved in fewer disciplinary incidents; and were more respectful of their classmates. The researchers offer lessons learned about the transition for other Catholic school leaders who may be considering such a change.

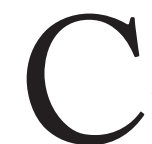

atholic schools in the United States are faced with the looming challenge of declining enrollments. From 2000-20I2, there was a $23 \%$ reduction in student enrollment nationally, and $24 \%$ of Catholic schools were either closed or consolidated with other schools. The current number of students enrolled in Catholic schools has dropped to approximately 2 million following a peak enrollment of 5.2 million students in the I96os. The schools most affected by the decline in enrollments are the elementary schools, which will likely affect middle and high schools enrollments in the future (National Catholic Educational Association, 20II).

In addition to closing and consolidating Catholic schools, school districts have developed strategies to deal with decreased enrollments. For instance, Catholic schools have developed collaborative decision-making processes to deal with restructuring and fund-raising, and others have developed marketing and fund-raising programs (Concoran, Christianson, Blaschko, \& Suydam, 
2007). In a national study of urban Catholic schools, Goldschmidt and Walsh (2oII) identified multiple governance and fund-raising strategies to stave off school closures. Urban Catholic schools have formed consortia to consolidate administrative and operational costs while others are comanaged by a parish, diocese, and university. Other strategies include starting large-scale scholarship drives, patron programs, endowment programs, and securing state and federal funding through voucher and tax credit programs, and transportation programs in high-poverty Catholic schools (Goldschmidt \& Walsh, 20II). Another option is to introduce multi-grade classrooms to both deal with enrollment challenges and to meet the development needs of students (Concoran et al., 2007).

Rural communities and sparsely populated regions have coped with low enrollments by using multi-grade classrooms, which Veenman (1995) distinguishes from multiage classrooms. In the former, the same instructor teaches students from two or more grades at the same time primarily as an administrative device to consolidate school staffing, thus addressing declining enrollments or uneven class size. The multiage classroom, on the other hand, has the same teacher-student configuration, but the reasons for using this format are educational and pedagogical (Veenman, 1995). With the latter, educators believe that students are offered the best-individualized and developmentally appropriate education (Finegan, 200I). In other words, they focus on students' individual needs, talents, and interests, and rather than standardizing the classroom experience, the multiage educator begins with the assumption that all children are different and should be taught accordingly (Finegan, 200I). Though the terms multiage and multi-grade are occasionally used interchangeably, most researchers differentiate between the two, stemming from the underlying rationale for instituting the mixed age classroom (Mason \& Burns, 1996; Veenman, 1995). These distinctions will be further explained below.

In this article, we examine one urban Catholic school's transition to a multi-grade classroom when student enrollments dramatically dropped. Saint George Parish School is a small K-8 Catholic school (approximately I4O students) in Stockton, California, with a principal and five teachers. The school, like other Catholic parish schools, provides religious education in addition to the conventional education that students receive in public schools. Established from two schools when declining enrollment forced consolidation, Saint George adopted a multi-grade approach in August 2008. The school is comprised of approximately 50\% Hispanic and 50\% Filipino students. The families are considered low income, with over $70 \%$ of the students eligible for 
free or reduced lunches, and Ioo\% of students receiving some form of financial aid.

The multi-grade classrooms are organized into four "families," named for Catholic leaders with strong reputations for social justice and service. For example, one family is named for Archbishop Oscar Romero who lost his life while working with the campesinos of El Salvador and another for Mother Teresa of Calcutta, the founder of the Missionaries of Charity. The specific grade combinations in five classrooms are as follows: (I) kindergarten; (2) grades I and 2; (3) 3 and 4; (4) 5 and 6; and, (5) 7 and 8. Each combined class has one instructor only, and the students stay with the same teacher for two years, reaping many of the benefits of looping, a school structure where children remain with the same teacher for two or more years (Franz, Thompson, Fuller, Hare, Miller, \& Walker, 2oro). This arrangement is in contrast to the previous school structure where there were single-graded classes with an individual instructor.

In October 2009, approximately a year after initiating the multi-grade classroom, the principal at Saint George extended an invitation to several faculty members from the Kalmanovitz School of Education at Saint Mary's College of California (SMC) to consider creating a "small school lab" at the school, hoping to develop "a creative program that would be beneficial to all." At this point in the collaboration, the principal did not have a specific goal for the collaboration. Rather he emphasized that the school had "a strong faculty with a great willingness to learn and a solid parent corps that would also be willing to work." The collaboration between Saint George and the SMC research team began in December 2009. After meetings with the principal, teachers, and several parents, the initial focus for the collaboration was to help Saint George identify the benefits and challenges of their shift to multi-grade classrooms and to identify ways to improve upon this new model of classroom instruction. The project was designed to be a participatory action research project where the Saint George staff and parents would be involved in each step of the research process, including designing the data collection instruments, participating in the data analysis, and identifying recommendations for continued improvement.

To begin the process, the SMC researchers and Saint George staff and parents agreed to collect baseline data and to identify what the impact of the multi-grade classrooms have been on the school. For this phase of the process, three research questions were identified: 
I. What is the parents' level of satisfaction with their child's educational experience at Saint George?

2. What impact, if any, has the shift to the multi-grade classroom had on student achievement, attendance, and tardiness?

3. What are the benefits and challenges of the multi-grade classroom in the eyes of the parents and teaching staff at Saint George?

\section{Multi-Grade and Multiage Education}

At one point in history, education was largely restricted to the privileged classes, who were taught by tutors or teachers in largely individualized settings. With the need to educate a largely illiterate populace and to provide skills training, publicly supported education in the United States was introduced in the early I8oos. Horace Mann introduced the graded concept of education in midcentury, and by the latter half of the I8oos, graded instruction was considered the normal way of schooling (Yarborough \& Johnson, 2000). Even though there were one-room schoolhouses in rural areas as late as the early igoos, as the nation's population and new public schools grew, the one-room schoolhouse became obsolete.

Though there have been efforts to promote schools without designated grade levels (Anderson, 1992) and to champion multiage education (Pardini, 2005), most schools are now organized by single grade levels, and the multigrade classroom is viewed by many educators and parents as an inferior form of education (Benvueniste \& McEwan, 2000; Veenman, 1995). When schools are forced to revert to the multi-grade classroom for enrollment reasons, however, they often claim the same academic and non-cognitive advantages as the single-graded classroom, thus making "a virtue out of necessity" (Veenman, I995, 322).

Though still the minority in $\mathrm{K}-\mathrm{I} 2$ educational settings, there is some evidence to suggest that students in multi-grade and multiage classes fare as well, if not better, than students in single-grade classrooms. For example, Pratt (I986) reviewed 30 experimental studies conducted between I948 and I983 in the United States and Canada to compare the effectiveness of multi-grade versus single-grade education. He concluded that there was no consistent academic benefit to age segregation-the dominant school structure in North American schools-but rather there are some affective and social advantages of multiage groupings. Similarly, Veenman (1995) conducted a meta-analysis 
of 56 studies of multi-grade and multiage classrooms from I2 countries. Veenman determined that there were no significant differences between classrooms with either multiage or multi-grade groupings and single-graded classrooms in the areas of cognitive or non-cognitive growth. He deduced that "there is no empirical evidence for the assumption that student learning may suffer in multi-grade and multi-age classrooms" (Veenman, 1995, 319).

Mason and Burns (1996), however, took exception to Veenman's (1995) conclusions, critiquing his methodology and asserting that the researcher did not take into consideration two key factors: selection bias and lower quality teaching. They contended that principals place more cooperative and advanced students in multi-grade classrooms to reduce the burden on the teachers and similarly, better teachers are assigned to the multi-grade classroom. In contrast to Veenman's analysis, Mason and Burns (1996) suggest that the multi-grade classroom has at least a small negative effect on student achievement and potentially an adverse impact on teacher motivation.

\section{Multi-Grade Education}

As described previously, Veenman (1995) made a distinction between the multi-grade and multiaged classrooms. Generally the former is instituted for administrative reasons and the latter, for perceived pedagogical improvements. It is likely that educators teaching in sparsely populated rural areas using the multi-grade format, face the greatest challenges of implementing the mixed age classroom. For example, Benvueniste and McEwan (2000) examined the conditions under which a well-developed multi-grade classroom approach called Escuela Nuevo would work in rural Columbia. Finding that there was a great deal of variation in teacher use of the recommended multi-grade instructional techniques, they used regression analysis to determine which factors accounted for the variation. Benvueniste and McEwan (2000) found that capacity-building through in-service training was an important factor, but more likely, the will to teach accounted for the greatest variation in the adoption of new pedagogies. The teachers' commitment and motivation were influenced by various reasons such as the multi-grade approach was not the norm or accepted practice for quality education. For most teachers, this approach was more cognitively and emotionally demanding for them, and they often did not have access to appropriate instructional materials for teaching students of multiple ages. Finally, some teachers lacked a sense of "ownership" for the method because the approach had become "canned" and dropped into new school sites. 
In another study with teachers in small rural schools in Iceland, Aoalsteinsdottir (2008) explored the degree to which a small school with multi-grade classrooms offered an educational advantage to the children even though the multi-grade approach was used for administrative reasons. The benefits that the researcher anticipated were not realized in part because the teachers were poorly trained, they were often isolated and lacked resources for curriculum development, and they were predominantly part-timers with little commitment to their work. Additionally, the teachers did not employ differentiated instructional methods to meet the needs of the individual students in the multi-grade classroom. In these two studies, it appears that the multi-grade approach suffered because of circumstances related to how they were implemented rather than the educational merits of the approach itself.

\section{Multiage Classrooms}

There is noticeably more research on multiage classrooms than multi-grade classrooms, especially in the United States. Progressive schools such as Montessori and Reggio Emilia schools intentionally employ a multiage approach to teaching students, built on the assumption that it can be individualized to meet the developmental needs of students (Finegan, 200I). Many public and charter schools are also attracted to this method, which includes a set of generally agreed-upon criteria such as replacement of grade labels, discontinuation of competitive-comparative evaluation systems, combined classrooms with at least two age cohorts, fluid groupings for instructional purposes, and the use of flexible, whole-child oriented curricula (Anderson, I993).

Proponents of multiage education report that students benefit academically, emotionally, and socially by being in a mixed-age classroom. For example, McClellan and Kinsey (1997) tested this belief in their quantitative study, exploring the impact of the classroom format on pro-social behavior, friendship behavior, aggression, and negative behavior. They found that there were significant differences between students enrolled in the mixed-age classrooms versus the single-age grouping on all four characteristics in the direction of favoring the mixed-age classrooms (McClellan \& Kinsey, I997).

Ong, Allison, and Haladyna (2000) conducted a quantitative study to explore the impact of multiage classrooms, gender, low-income status, and ethnicity on third grade students' reading, writing, and math test scores. The students overall fared better on the achievement tests when enrolled in multiage classrooms, and statistically significant differences were found on all three 
tests when multiage versus single-grade classes were compared. When examined closer, however, classroom type made no differences for the low-income and Hispanic students. The authors concluded that the study offered promising support for the multiage classroom, but warned that additional work was needed to see success for the traditionally lower-achieving groups.

Aina (200I) conducted a qualitative study to identify teacher, student, and parent perceptions about multiage education. She found that with mixed-age classrooms, children progress at their own pace, individuality is valued, labels are not used to identify students at different levels of academic achievement, and competitiveness is deemphasized. Students also develop stronger relationships with their peers and teachers since they are with them for at least two years. On the other hand, Aina (200I) pointed out that parents are often uninformed about multiage education, teachers may not be adequately trained in appropriate instructional techniques, and teachers have (or fear having) a heavier workload.

Espinosa and Chen (200I) examined teacher attitudes and practices in their mixed methods longitudinal study about technology and multiage education. After two years, $100 \%$ of the teachers in the study embraced the multiage approach and increasingly used developmentally appropriate instructional practices. During the third year, however, $22 \%$ of the teachers expressed negative feelings about multiage education, doubting their own effectiveness. The researchers suggest that ongoing support and mentoring are needed in order to institutionalize systemic change toward multiaged education.

There are numerous articles that explore anecdotal data about the benefits and challenges of multiage education. For instance, Heins, Tichenor, and Coggins (2000) described the value of the multiage approach in their school, namely, it makes learning more developmentally appropriate, children can make continuous progress at their own rate, and flexible groupings allow students to excel in certain areas with different peers. Hoffman (2002) reinforced the importance of flexible groups, discussing how they can be used effectively in multiage classrooms to help students learn to accept differences in abilities and social behaviors (p. 49). Kappler and Roelike (2002) discussed the importance of teachers who teach multiage classrooms to change their teaching style and assessment methods. In their view, the teacher's role centered largely on creating open-ended activities and learning centers to accommodate different student needs and shifting from assessments where students are compared to other students to flexible assessments based on individual student performance. Mellinger (2005) discussed how her school gradually adopted a multi- 
age approach, resulting in increased test scores over a six-year period. She also described a strategy to educate both the teachers and parents who were especially concerned about the shift away from the more traditional single-graded classroom. She ended with the following: "The multiage program requires an enormous amount of long-range planning and detailed daily preparations by teachers... which has become even [more difficult] due to the state's required testing of specific subject standards in particular grade levels" (p. 25).

In her article discussing the decline in multiage classrooms, Pardini (2005) discussed the many factors that have contributed to this trend. For instance, she reported that some educators blame the No Child Left Behind legislation with its emphasis on standardized, grade-level testing as undermining the multiage approach. Others, according to Pardini (2005), suggest that multiage classrooms are the casualty of a general trend toward teacher-centeredness rather than student-centeredness. It is decidedly more difficult to teach multiple age groups especially when there is such variability within each age grouping. Further, given the standard of graded education, many parents do not understand the mission and philosophy underlying the multiage approach. She concluded her analysis, however, with hope by quoting an administrator who is committed to multiage instruction:

Progressive minded administrators who believe strongly in multiage and have a vision of how to implement it and a staff to pull it off don't need to worry about test scores. If the teaching is high quality and the curriculum is comprehensive, test scores will fall into place (Pardini, 2005, np).

\section{Methodology}

Over an I8-month period, the SMC research team met with the teaching staff and parents at Saint George to develop data collection instruments for this project. The team itself did not provide professional development on how to successfully implement multi-graded classrooms, but in keeping with participatory action research helped the teaching staff and parents clarify their questions about the multi-grade approach and design appropriate data collection tools. This article focuses on three main sources of data: parent surveys; schoolmaintained statistics on absenteeism, tardiness, and test scores; and parent and teacher interviews. 


\section{Parent Surveys}

The survey that was distributed to the parents was modeled on one developed by the Western Catholic Education Association to assess parent satisfaction with their child's education. In contrast to the other two data sources, the surveys did not focus on the impact of the multi-grade classroom. The survey, focusing on the parents' reasons for sending their children to Saint George and their satisfaction with various aspects of the children's educational experience, included I7 items with one open-ended question for comments. Given the collaborative focus of this project, the teachers and several parents gave input into the survey design, critiqued the first draft, and pilot tested the second draft before it was finalized. Once finalized, the principal sent the surveys with an accompanying letter to the parents before school-wide parent-teacher conferences, asking them to bring their completed surveys when they met with their child's teacher. The parents deposited their completed surveys in a box to ensure anonymity. As a result of this careful planning, $84 \%(\mathrm{~N}=92)$ of the parents completed the surveys. Basic descriptive statistics including mean scores and percentages were computed for the survey data as well as t-tests for independent samples.

\section{School Data}

The SMC research team examined school-level data on absences, tardiness, and test scores over a three-year period: one year before the shift to the multigrade classroom and two subsequent years. Data were obtained for only those students $(N=63)$ who were enrolled at Saint George both before and after the shift. Basic descriptive statistics such as mean scores and averages were computed as well as t-tests when appropriate.

\section{Parent and Teacher Interviews}

To develop the questions for the interviews, the research team invited the parents and teachers to identify the information they wanted to collect in order to assess the effectiveness of the multi-grade classroom. After soliciting feedback from the Saint George participants, the SMC research team generated interview questions, which were then reviewed by Saint George parents and teachers. The interview questions were revised based on feedback. In contrast to the parent surveys, these questions focused on the differences the parents and teachers observed after the implementation of the multi-grade classroom. 
Originally written for the parents, the interview questions were then slightly revised for the teacher interviews.

The parent interviews were conducted on a Sunday that coincided with Saint George's Open House. The principal identified parents who had children at Saint George before and after the shift to the multi-grade classroom, and he then randomly selected parents for the interviews. The principal and teachers were interviewed several weeks later; all interviewees signed an informed consent form. A total of I4 individuals were interviewed: one principal, five teachers, and eight parents.

A qualitative case study approach to data reduction was used to analyze the interview results. The interviews were recorded, transcribed, and then analyzed for themes or patterns (Miles \& Huberman, I994). The use of repeated phrases to particular questions allowed researchers to identify propositions regarding the relationship between parent perceptions about Saint George before and after multi-grade classrooms were instituted.

Once all three sources of data were tabulated and organized, the teachers and parents were invited to join in an analysis of the findings and to generate conclusions from the research.

\section{Findings}

\section{Parent Surveys}

As mentioned, 92 parents (84\%) completed the surveys about their level of satisfaction with their child's education at Saint George Parish School. Of the total, $79 \%$ of the surveys were completed by females and 21\% by males. When parents were asked to select the three most important reasons they sent their child to Saint George, $73 \%$ chose academic excellence; 70\% Catholic faith formation; and 63\% Catholic values. Fewer than $50 \%$ selected each of the other options: location, discipline, teachers, or safe environment. Regarding the parents' level of satisfaction with their child's experience at Saint George, the parents were overwhelmingly satisfied. Specifically, when asked how satisfied they were with each of the options above (academic excellence, Catholic faith formation, etc.) the mean for all items combined was 3.62 on a scale with I (not satisfied) to 4 (very satisfied).

There was a great deal of congruence between what the parents identified as most important in their child's education and their level of satisfaction. For 
example, $73 \%$ of the parents selected Saint George for academic excellence, and they were extremely satisfied with the level of academic quality at Saint George with a mean score of 3.78 out of 4 . (See Table I for a full listing of the reasons the parents chose Saint George and their level of satisfaction.) The one area where there was a discrepancy was related to the teachers. Only $27 \%$ of the parents identified the teachers as one of the three most important reasons for sending their child to Saint George though they rated their level of satisfaction with the teachers on par with their satisfaction with the Catholic values that are taught.

When asked about their level of agreement with a series of questions about Saint George, the parents again were overwhelmingly positive. On the following statements, $99-100 \%$ of the parents either agreed or strongly agreed with the following statement:

Table 1: Reasons for Selecting Saint George and Level of Satisfaction

\begin{tabular}{lcc}
\hline Category & $\begin{array}{c}\text { Percentage Selected as } \\
\text { Top Three Reasons }\end{array}$ & $\begin{array}{c}\text { Mean score on } \\
\text { Satisfaction }\end{array}$ \\
\hline Academic excellence & $73 \%$ & 3.60 \\
Catholic faith formation & $70 \%$ & 3.73 \\
Catholic values & $63 \%$ & 3.78 \\
Discipline & $49 \%$ & 3.62 \\
Teachers & $27 \%$ & 3.78 \\
Safe environment & $30 \%$ & 3.46 \\
Location & $3 \%$ & 3.34 \\
\hline
\end{tabular}

Note: The scale for the mean scores is $1=$ Not at all $-4=$ Extremely Satisfied

- Overall, I am satisfied with St. George's academic curriculum for my child.

- I am satisfied with the amount of homework the school places on my child.

- Overall, my child receives a high quality education at Saint George.

- In general, my child looks forward to going to school each day at Saint George.

- In general, I am satisfied with St. George's teaching staff.

- I am satisfied with the Catholic instruction my child receives at St. George.

- I am satisfied with the number of students in my child's family (class) at St. George.

- In general, I am satisfied with the amount of opportunity for family involvement at St. George. 
In only one category-satisfaction with the physical environment and appearance of St. George-did the satisfaction dip below 99\%. In this instance, $16 \%$ were dissatisfied or strongly dissatisfied with the physical environment.

Of the 92 parents, only 27 (29\%) indicated that they have children who had previously graduated from Saint George. When asked about their students' preparation for high school, the average score was 3.52 on a scale of I (not at all prepared) to 4 (very well prepared). In other words, $94 \%$ of these parents indicated that the students were either well prepared or very well prepared for high school.

In summary, from the parent responses on the survey, they are overwhelmingly satisfied with their child's educational experience at Saint George. Further, of the parents with a child who graduated from the school, $94 \%$ believe that their child was either well prepared or very well prepared for high school. The parents' perception about their child's preparedness for high school matches the data obtained from the most recent high school placement scores. Saint George students were on average one year above their expected grade level on their entrance exams for Catholic high school.

\section{School-level Data}

The principal at Saint George Parish School has collected data on student tardiness, absenteeism, and test scores from the 2007-2008 school year, the year prior to the school adopting a multi-grade approach through the 2009-20IO school year. Student scores included in this analysis reflect the students who attended Saint George during all three academic years; it does not represent all Saint George students. The researchers wanted to compare the same students' performance before Saint George moved to a multi-grade classroom and after the change.

Student Tardiness and Absenteeism. In the table below, the mean score and overall percentage of students who were tardy and absence from school are summarized. This data is based on the assumption that students were enrolled in 180 days of instruction. The mean score can be interpreted as the average student was tardy almost 6 days out of 180 in 2007-2008 while the percentage indicates that out of I80 days, students were on average tardy $3.3 \%$ of the time in 2007-2008.

As can be seen, the amount of tardiness dropped significantly in 2008-2009 and then jumped back up in 2009-2010. In fact, the differences in mean scores were significantly different in a positive direction from 2007-2008 to 2008- 
2009 and then again in 2008-2009 to 2009-2010, but in a negative direction. For the absences, they have slightly increased each year though there are no

Table 2: Tardiness and Absenteeism

\begin{tabular}{llllll}
\hline & \multicolumn{3}{c}{ Tardies } & Absences \\
\hline Year & \# of Students & Mean & Percentage & Mean & Percentage \\
$2007-08$ & 63 & 5.98 & $3.3 \%$ & 5.8 & $3.2 \%$ \\
$2008-09$ & 63 & 1.83 & $1.0 \%$ & 6.0 & $3.3 \%$ \\
$2009-10$ & 63 & 5.8 & $3.6 \%$ & 6.62 & $3.7 \%$ \\
\hline
\end{tabular}

significant differences between the three years when t-tests were run.

Student Test Scores. Students at Saint George Parish School take standardized tests each fall, which are administered to all Catholic schools within the Diocese of Stockton. For this study, achievement data from academic years 2007-2008 through 2009-2010 were examined to determine the average grade level equivalency of students in grades 4 through 8 at Saint George Parish School. The data are disaggregated to show student performance by subject area, specifically reading, math, and science. Religion scores were not included in this analysis.

Given the small sample sizes for each grade level in this study, student scores for the sample were combined to increase the number of participants and the validity of the statistical analyses. With the combined sample of 70 students, those students who scored at grade level in two or more of the selected subjects (reading, math, and science) were identified for each of the three years. This number represents fourth through eight grade students who were enrolled at Saint George for the year before the shift to the multi-grade classroom and the two years after.

In $2007-2008,79 \%$ of the students scored at their grade level in two or more subjects; in $2008-2009,81 \%$ of students scored at their grade level in two or more subjects; and in 2009-2010, $78 \%$ of students scored at grade level in at least two of the three subject areas. The 2009-20Io data were further analyzed to assess how well the students scored in the three subject areas. In English language/reading, $72 \%$ of the students were at grade level; in math $86 \%$ of students were at grade level; and in science, $74 \%$ of students were at grade level. These data suggest that there has been no significant change in aggregate test scores when comparing all students before and after the shift to the multigrade classroom.

In conclusion, the results from these analyses demonstrate that students in 
grades 4 through 8 maintained the same levels of performance as measured by grade level proficiency in reading, math, or science. For the three-year period, approximately $80 \%$ of the sample was performing at grade level in at least two of the three subject areas. In addition, on average, the students in this Saint George sample were operating at a grade level approximately I.5 higher than the grade in which they were enrolled. The shift to multi-grade classrooms did not negatively impact student academic performance as measured by the specific standardized test. Additional data, however, should be collected in subsequent academic years to provide an extended picture of how changes in classroom structure may or may not influence student achievement.

\section{Parent and Teacher Interviews}

With the interviews, the goal was to find common patterns and language in the participants' responses as they answered questions regarding the effects of the shift to multi-grade classrooms. After examining, coding, and charting data gleaned from interview transcriptions, five distinct themes emerged. These themes were: family-like atmosphere; emphasis on values; parental involvement; peer relationships; and, differentiated instruction.

Family-Like Atmosphere. A family-like atmosphere prevails over the Saint George campus. During interviews five out of eight parents used words such as "family" or "caring" to describe Saint George when responding to the question: How is Saint George different from other elementary schools in Stockton? One parent exclaimed, "When the teachers talk to [the students], they talk to them from the heart...they want them to do good in life and they want them to be successful. I'm glad we chose this school." Another parent referred to his son's class as a "family class" with the teacher serving as a parental figure who was explicitly teaching consequences for actions. "I actually see that he's grown more responsible and I think it all boils down to the teachers."

The most common compliment the parents paid was a reference to Saint George's "family-like feel." The small school size allows adults to recognize all children by name. Given the enrollment of approximately I40 students, Saint George feels more like a one-room schoolhouse of yesteryear than an urban school. There are no strangers at Saint George, and teachers have become an extension of the student's natural families. By having the students for two years, the teachers get to know them better, they have more time to see the students change and grow, and over time, they feel responsible for the children's development, much like a parent does. Additionally, the teachers use language 
to emphasize the family, especially since instituting the family designations when the multi-grade classroom was implemented, and they participate with students in family-like activities such as going to Mass, eating with them, and going on field trips.

The use of faith to create a family atmosphere complements Saint George's choice to have multi-graded classrooms, providing cooperative learning opportunities for students in a familial setting. Multi-graded classrooms have created the opportunity for students to nurture other students and be nurtured by them. The perspective that boundaries between school and life beyond school blur, and the revelation that staff cares about the students of Saint George in a familial way is shared by both teachers and parents alike.

Emphasis on Values. Values clearly play an important role in Catholic education, and parents referred to choosing Saint George specifically because they knew the important role Catholic values play in the educational philosophy of the school. Parents who enroll their children in Catholic schools desire an experience that exposes them to the Catholic faith daily and to a value system that reinforces the values of the parish community.

While the interviewees emphasized the importance of value-based education as a critical aspect of the Saint George experience, the multi-grade classroom adds an additional dimension to the importance of values. For example, the words shared responsibility, leadership, and respect were repeatedly documented in the interviews. According to the parents, students developed behaviors that included helping siblings with schoolwork, extending service from school to the parish, enlisting parents in the school improvement process, and donating personal income to homeless shelters. Parents link the development of these values to the classroom experience and in part, to the multi-grade classroom. By design, teaching and learning in the multi-grade classroom is based on the principles of peer instruction and support, and students lead many of the day-to-day activities. These activities help the students develop empathy and respect for their fellow classmates (Aina, 20or; McClelland \& Kinsey, 1997). As explained by one parent: "they actually made him to have a good heart... I'm proud of this school that they actually teach their students... to help others."

Parent Involvement. The multi-grade approach to education deliberately fosters opportunities for parent involvement. Given Saint George's focus on creating a family-like atmosphere within the classroom, members of the family of origin are often invited to join in with the "extended family." All eight parents interviewed reported a high level of involvement in their child's education 
at Saint George. Though many of these parents reported they were involved prior to the shift to multi-grade classrooms, three parents reported their involvement had increased partially because the opportunity for involvement had increased.

Multi-grade educators embrace the importance of social development in the educational process. Students experience learning in their classroom, in their parish hall, and on field trips outside of their neighborhood. There are so many opportunities for extended learning in the multi-grade experience that students solicit their parents' participation for extended trips, enthusiastically inviting them to join the experience. "He is calling me when there's something that's going on or when there's something that's going to happen. Whatever they have going on here at school he'll call me or tell me...he always wants me to be involved."

Peer Relationships. The structure and culture of Saint George created after the shift to the multi-grade classroom has helped to develop relational and leadership skills among students. Parents have been satisfied with the peer relationships of Saint George students. One parent expressed appreciation that her children who are one year apart can collaborate and complete their homework assignments together. The principal shed light on the past history of the campus climate and is excited about how discipline issues have decreased over the past few years. He stated:

While there may have been other significant issues involved in the decrease in discipline issues at Saint George, it seems that the shift to multi-grade classrooms has played an integral role in creating a more positive campus culture. This is especially true in the area of positive modeling and peer leadership.

Leadership skills seem to be interwoven into the fabric of the multi-grade classroom. One teacher gives an example by explaining how the lower grade students look up to the older students because they have more experience and more knowledge. She also points out that as she teaches, she depends upon her older students to help their younger peers with concepts not fully understood. Reflecting upon her class she states, "It's almost like I'm not teaching two grades." This example signifies a two-way learning process in which students reinforce their own learning by teaching it to their younger peers.

The teachers, principal, and parents noted that the mixture of older and younger students within the classroom has positively affected student disci- 
pline and behavior as well as the overall leadership abilities of most students. Comments from participants indicated that the multi-grade classroom challenges Saint George students to model behavior for their younger counterparts and to hold themselves accountable to higher standards. They characterize students as being more respectful and marvel in how the older students "take care of the younger students." In her response, one teacher highlighted her observations of the interactions of younger and older students: "We were [working on a class play] and my class is small this year. I needed 34 students, so I pulled students from next door... and they are doing a great job with the [older students]. They are not afraid to volunteer, not afraid to step up to the plate." This type of student interaction and the notion that students could interact and contribute in a play with students two years ahead of them would not likely have materialized before the shift to the multi-grade classroom.

A core value of Saint George's culture is a strong belief in family, which in highly functional families contributes to positive relationships among the family members or in this instance, with students in the same multi-grade classroom. Attachment and influence between older and younger learners was referenced as a powerful difference when parents reflected on how Saint George has changed after the institution of multi-grade classrooms. Parents noticed students "adopting" each other, calling on each other with family names (brother), and developing cross-age relationships in Saint George's inclusive environment. One parent summed up the typical parents' sentiment:

I think that for my second grader, he gets along well with all of them... If it's a smaller child than him....he's very careful...he's very protective... if it's an older kid, he sees them more like a brother, because he doesn't have brothers...so he's adopting people.

Differentiated Instruction. The concept of differentiation, or a personalization of instruction that meets the need of each individual student, is well understood, but doing this for a group of 20 or more students on an ongoing basis is difficult to accomplish. Therefore, many teachers resort to teaching to the middle of their students' academic abilities in their grade level classrooms. In the multi-grade classroom, the challenge of differentiation is exacerbated, given the various levels of student socio-emotional growth, cognitive functioning, and maturity. When the shift to the multi-grade classroom was first initiated at Saint George, the teachers received limited professional development in how to differentiate instruction in the mixed-aged classroom. At that 
time, the goal was to accommodate fewer students in fewer classrooms with fewer teachers, and little change was required in the educational model.

The Saint George teachers, the principal, and a sample of parents revealed that because of the shift to the multi-grade classroom, differentiation has become a major focal point for the school. One teacher characterized the implementation of differentiation strategies as inevitable. She insists that there is simply a "need to do it." The majority of teachers and one parent explicitly stated that they felt the shift to multi-grade classrooms resulted in a heightened awareness of the necessity for differentiation. There was also consensus among participants that there are significant benefits to the multi-grade level classroom. For example, teachers noticed a positive fluidity among age groups. Even though there was a difference in student ages of one to three years, students socialized and interacted on a level socio-emotional plane.

Differentiation occurs even when the teacher is not directly involved. For example, one parent stated:

Another more observable benefit to the multi-grade classroom is that many students now have access to more rigorous content at a younger age. This structure has the potential to be equally beneficial for those older students in need of remediation of certain key skills, which are cycled back because they are housed with students at a slightly lower grade level.

One teacher expressed her satisfaction with the multi-grade classroom by illuminating how the structure of the class has benefited all students. In reference to the range of academic skills that students may have, she explained that students may now move up or down as they need to. For example, sixth grade students who need more challenge in mathematics actually go up to the seventh and eighth grade combination class during the mathematics period. Another teacher claims that the shift to the multi-grade classroom has "made it more interesting to [the students]."

Differentiation at Saint George is more than just an academic process and seeps over into the socio-emotional development of students. The teachers attend to both the academic and socio-emotional needs of each student, and it has not come without challenges. One astute parent noted that in order to adequately differentiate for ranges of ages, academic levels, and socioeconomic levels, the teachers must carefully plan and implement instructional strategies that may be new or difficult. Teachers in particular articulated the challenge 
of the increased workload that differentiation brings. One teacher in particular stated that she felt she was "doing too much." Another teacher acknowledged that the change in environment during differentiation including grouping and student talk was initially uncomfortable for her. The teachers' responses with this change in practice are neither uncommon nor unexpected.

In summary, while there have been challenges, there have also been significant, possibly unforeseen benefits, to the school's shift to multi-grade education. As noted by those interviewed, the students blossomed in the family-like atmosphere at Saint George, establishing strong, positive relationships with their peers. They developed leadership skills both within the classroom and at home, acquired values that are congruent with the teachings of the Catholic Church, and challenged themselves both socially and academically.

\section{Lessons Learned}

Data suggest that parents at Saint George Parish Elementary are extremely satisfied with their children's education, the students are doing as well academically as before the multi-grade classroom was instituted, and the parents and teachers are pleased with the non-cognitive benefits resulting from the shift to multi-grade classrooms. It is difficult, however, to tease out what accounts for these impressive results: the Catholic school environment; the small student enrollment; or the multi-grade classroom? To explore these questions and in keeping with the collaborative nature of the study, the researchers and Saint George staff jointly analyzed the data to better understand the research findings.

The joint exploration began with an examination of what accounted for such positive and extremely impressive results. The Saint George staff noted that the parents have a clear choice between Saint George and other schools in the area, and they have made a conscious choice to enroll their children at Saint George. Similarly, the students want to go to the school. So the parents and children were predisposed to be satisfied with the education because they have chosen the school.

There were additional factors related to the school culture and size that contributed to the children's achievement and parents' satisfaction. They include:

I. The family atmosphere contributes to the high level of parent and teacher satisfaction. The emphasis on family has been an important 
part of the culture for years, predating the current principal and staff. At Saint George, children feel safe in this "family"; they feel welcomed. There is little drama (cliques, fights, etc.) that they hear about in other schools. And especially for the upper grades, the students do not have to change teachers and classrooms, contributing to their feelings of safety.

2. There is a great deal of socioeconomic homogeneity at the school, again contributing to the feeling of safety. In contrast to some other Catholic schools, there are no children from wealthy families and none from extremely poor families. In general, the families are all working class families so status differences based on wealth are minimal.

3. Students receive a great deal of individual attention at Saint George, given the class size, helping to contribute to the parent satisfaction and student academic achievement.

For the next level of analysis, the teachers and researchers answered the following question: To what extent can the shift to the multi-grade classroom explain the positive results of this research? In response to this question, the family theme surfaced again along with a new emphasis of differentiation.

I. By having the students for two years, the teachers get to know them better-both their strengths and their needs. They spend less time on assessing their students' skills and more time on instruction as has been found in studies that examined looping (DelViscio \& Muffs, 2007). With this model, the students feel comfortable because the expectations are clear; they are familiar with the rules, procedures, and routines (Pratt, 2009). Additionally, given the shared culture among the teachers, the students feel safe even when they are promoted to a new class because the expectations will be similar, and they will already know (or know about) the new instructor.

2. The teachers believe that when the students feel comfortable and safe in the classroom, there are fewer disciplinary problems, allowing them to focus on instruction rather than classroom management. This, in part, can help explain why so many of the students at Saint George are at or above grade-level proficiency.

3. The multiage classroom more closely resembles the family unit than the single-grade classroom. As mentioned, there are older children in 
the class who teach the younger student about how "things are done in the class." In effect, they orient the new students to the culture of the classroom, and the younger students look to the older students for guidance and support, much like the relationship between older and younger siblings.

4. When the school shifted to the multi-grade classroom, new names were used to replace the original grade levels. The creation of classroom designations using the names of Catholic social justice leaders reinforced the importance of the family focus. As the principal stated, the creation of the family designation was "an outward sign on an inward concept."

5. The need to differentiate instruction, given the diverse needs of the students, requires that teachers develop a personal relationship with each child. Having more time with the students increases the likelihood that the teachers can find the best way to instruct them. For example, if a teacher is initially using one approach in working with a student and it does not work, she has another year and one-half to develop new strategies for instruction. Naturally with this kind of dedication to meeting the needs of students, the teachers have a great deal of interaction with the students, and the students (and parents) are confident that the teachers care about them and have their best interest at heart.

\section{Conclusion}

Though the multi-grade classroom was instituted at Saint George because of declining enrollments, the research findings suggest that there have been additional benefits beyond administrative efficiencies. While the transition to multi-grade classrooms did not have a significant impact on student outcomes as measured by absences, tardiness, or academic performance, it did have a perceived benefit on other areas. Using Veenman's (1995) definition, it appears that Saint George staff introduced the multi-grade classroom for managerial reasons but has begun to reap the psychosocial benefits of the multiage classroom. For example, the students are more likely to nurture other students and be nurtured by them; assume shared responsibility and leadership in the classroom and at home; are involved in fewer disciplinary incidents; and are more respectful of their classmates.

This successful transition does not occur in all instances, as the research lit- 
erature has shown. For example, it is often difficult to shift from a single-graded to multi-graded classroom if the teacher commitment and professionalism is lacking and if the resources are limited (Aoalsteinsdottir, 2008; Benvueniste \& McEwan, 2000). The mixed-age classroom, however, seems particularly well suited to Saint George Parish Elementary where there is a strong family-oriented culture emphasizing Catholic values, academic achievement, and discipline. Additionally, the teachers view their profession as a calling, and they have been willing to dedicate the time required to learn about and implement a multi-grade approach with the ultimate focus on the development of the whole child. In this way, Saint George is similar to Montessori schools, which have for over a century championed the multiage approach to education. Though this study offers promising results for small Catholic schools that have to transition to a multi-graded classroom for survival, additional research is needed to determine if similar results would occur in larger schools with lower-achieving students and different school cultures.

To continue the trajectory toward providing a high level of effective instruction to all students, the Saint George teachers recognize the need for more professional development to expand their repertoire of teaching strategies as well as to develop better systems for monitoring student achievement (Franz, Thompson, Fuller, Hare, Miller \& Walker, 20I0; Kappler \& Roelike, 2002, Ong, Allison, \& Haladyna, 2000). As mentioned, when the school shifted to the multi-grade model, the teachers received limited professional development in how to differentiate instruction in the mixed-aged classroom. But to truly reap the pedagogical benefits of multiage education and to institutionalize systemic school-wide change, ongoing support, mentoring, and professional development is needed (Espinosa \& Chen, 200I).

\section{References}

Aina, O.E. (200I). Maximizing learning in early childhood multiage classrooms: Child, teacher and parents perceptions. Early Childhood Education Journal, 28(4), 219-224. doi: Io.IO23/A:I009590724987.

Anderson, R.H. (I992). The nongraded elementary school: Lessons from history. Paper presented at the American Educational Research Association in San Francisco, CA.

Anderson, R.H. (1993). The return of the nongraded classroom. Principal, 72(3), 9-I2.

Aoalsteinsdottir, K. (2008). Small schools in north-east Iceland. Scandinavian Journal of Educational Research, 52(3), 225-242. doi.org/10.1080/00313830802025017. 
Benvueniste, L.A. \& McEwan, P.J. (2000). Constraints to implementing educational innovations: The case of multigrade schools. International Review of Education, $46(\mathrm{I} / 2)$, 3I-48. doi.org/IO.IO23/A:I003922321999.

Concoran, M., Christianson, A., Blaschko, T. \& Suydam, T. (2007). Chipperwa Area Catholic school report. Retrieved from http://www.macs.kI2.wi.us/admin/pdf/surveyo7.pdf.

DelViscio, J.L. \& Muffs, M.L. (2007). Regrouping students. School Administrator, 64(8), 2630.

Espinosa, L.M. \& Chen, W. J. (20or). The role of technology in supporting multiage classroom practices. Information Technology in Childhood Education, 5, 5-31.

Finegan, C. (200I). Alternative early childhood education: Reggio Emilia. Kappa Delta Pi Record, 37(2), 82-84. doi.org/10.1080/00228958.2001.10518468.

Franz, D.P., Thompson, N.L., Fuller, B., Hare, R.D., Miller, N.C., \& Walker, J. (2ого). Evaluating mathematics achievement of middle school students in a looping environment. School Science and Mathematics. IIO(6), 298-308. doi.org/Io.III/j.I9498594.2010.00038.x.

Goldschmidt, E.P. \&Walsh, M.E. (20II). Sustaining urban Catholic schools: An examination of governance models and funding strategies. Boston, MA: Boston College.

Heins, E.D., Tichenor, M.S., \& Coggins, C.J. (2000). Multiage classrooms: Putting theory into practice. Contemporary Education, $7 \mathrm{I}(3) \cdot 30-35$.

Hoffman, J. (2002). Flexible grouping strategies in the multiage classroom. Theory into Practice, 4 I (I), 47-52. doi.org/IO.I20//sI543042Itip4IOI 8.

Kappler, E. \& Roelike, C. (2002). The promise of multiage groupings. Kappa Delta Pi Record, 38(4), 165-169. doi.org/10.1080/00228958.2002.10516367.

Mason, R.B. \& Burns, D.A (1996). "Simply no worse and simply no better" may simply be wrong: A critique of Veenman's conclusion about multigrade classes. Review of Educational Research, 66(3), 307-322.

McClellan, D.E. \& Kinsey, S. (1997). Children's social behavior in relationship to participation in mixed-age or same-age classrooms. Paper presented at Biennial Meeting of the Society for Research in Child Development. EDRS - ED 4I8 77I.

Mellinger, S.R. (2005). Our long, winding road to multiage classrooms. School Administrator, $62(3), 24-25$.

Miles, M.B. \& Huberman, A.M. (1994). Qualitative data analysis. Thousand Oaks, CA: Sage Publications.

National Catholic Educational Association. (20II). United States Catholic Elementary and Secondary Schools 20I0-20II: The Annual Statistical Report on Schools, Enrollment and Staffing. Washington, DC: National Catholic Educational Association. Retrieved from http://www.ncea.org/news/AnnualDataReport.asp.

Ong, W., Allison, J., \& Haladyna, T.M. (2000). Student achievement of 3 rd graders in comparable single-age and multiage classrooms. Journal of Research in Childhood Education, I4(2), 205-I5. doi.org/IO.I080/02568540009594764.

Pardini, P. (2005). The slowdown of the multiage classroom. School Administrator, 62(3), 23-30. Pratt, D. (1986). On the merits of multiage classrooms. Research in Rural Education, 3(3), IIIII5.

Pratt, M.W. (2009) Looping to meet the needs of gifted children. Principal. May/June, 22-24. 
Veenman, S. (1995). Cognitive and noncognitive effects of multigrade and multi-age classes: A best-evidence synthesis. Review of Educational Research, 65, 319-8I.

Yarborough, B.H, \& Johnson, R.A. (2000). Nongraded schools: Why their promise has not been realized and should be reconsidered. Contemporary Schools, 7I(3), 42-48.

Rebecca Proehl is a professor in the EdD program within the Kalmanovitz School of Education at Saint Mary's College of CA. She currently teaches courses in leadership, organizational theory, organizational change, and innovation and advises dissertation students. Proehl has her master's degree in social work from Virginia Commonwealth University and her PhD from The Wright Institute in Berkeley, $C A$.

Shelese Douglas is a California credentialed teacher, teaching physical education and dance to middle school children in Stockton, CA. She has a master's degree in dance and dance education from Teachers College at Columbia University and is a doctoral candidate in the EdD program at Saint Mary's College of CA.

Dean Elias is a professor in the EdD program within the Kalmanovitz School of Education at Saint Mary's College of CA. He currently teaches courses in leadership, values, and ethics and advises dissertation students. Elias has a master's of divinity from Union Theological Seminary and his EdD from Teachers' College at Columbia University.

Anthony H. Johnson is the principal at El Capitan High School in the Merced Union High School District in California. He has a master's degree in education from $\mathrm{Na}$ tional University and is a doctoral candidate in the EdD program at Saint Mary's College of $C A$.

Wendy Westsmith is the principal at Northside Elementary School in Black Oak Mine Unified School District in California. Westsmith has a bachelor's and master's degree in communicative disorders with a focus on education of the deaffrom California State University at Fresno and is a doctoral candidate in the EdD program at Saint Mary's College of CA. 